\title{
The Protective Effect of Marigold Hydroalcoholic Extract in STZ-Induced Diabetic Rats: Evaluation of Cardiac and Pancreatic Biomarkers in the Serum
}

\author{
Esmaeel Ebrahimi, ${ }^{1}$ Saeed Shirali, ${ }^{2}$ and Rahman Talaei ${ }^{1}$ \\ ${ }^{1}$ Student Research Committee, Ahvaz Jundishapur University of Medical Sciences, Ahvaz, Iran \\ ${ }^{2}$ Hyperlipidemia Research Center, Department of Laboratory Sciences, School of Paramedical Sciences, \\ Ahvaz Jundishapur University of Medical Sciences, Ahvaz, Iran \\ Correspondence should be addressed to Saeed Shirali; saeed.shirali@gmail.com
}

Received 28 September 2015; Revised 10 December 2015; Accepted 20 December 2015

Academic Editor: Shamsul Hayat

Copyright (C) 2016 Esmaeel Ebrahimi et al. This is an open access article distributed under the Creative Commons Attribution License, which permits unrestricted use, distribution, and reproduction in any medium, provided the original work is properly cited.

\begin{abstract}
Diabetes mellitus is the most common endocrine disorder worldwide and it is usually along with complications such as retinopathy, neuropathy, nephropathy, and cardiovascular disease. The prevalence of diabetes is increasing and its treatment has created concerns in society. The use of herbal medicine can be helpful in the management of diabetes mellitus. The aim of this study was to investigate the protective effect of marigold hydroalcoholic extract under diabetes condition. A total of 36 male Wistar rats were randomly divided into four groups: normal control group, diabetic control group, and groups treated with $250 \mathrm{or} 500 \mathrm{mg} / \mathrm{kg}$ hydroalcoholic extract of marigold flower during four weeks. At the end of the study, the rats were anesthetized with ketamine/xylazine, and sampling was performed through cardiac puncture. The results showed that treatment with marigold improved body weight. In addition, we determined that marigold normalized the level of CK-MB, total CK, amylase, and lipase in a dose-dependent manner. Probably these effects resulted from antioxidant property of marigold; thus we suggest that marigold flower can be useful for reduction of diabetes complication.
\end{abstract}

\section{Introduction}

Heredity and environmental factors have an important role in diabetes. The disease is characterized by raised blood sugar levels due to the defects in insulin secretion or action $[1,2]$. Polyuria, polydipsia, and polyphagia are the symptoms of diabetes and hyperglycemia longer in diabetic condition leads to cardiovascular disease, retinopathy, and nerve disorders $[1,2]$. According to the latest survey in 219 countries, among people egad 20 to 79 years, 382 million people have diabetes mellitus and it is estimated that this number will reach 592 million in 2035 [3].

One of the disorders that occurs in diabetes is pancreatic exocrine dysfunction; studies have shown that insulin leads to reduction of lipase and amylase in an animal model of diabetes [4]. Diabetic ketoacidosis can lead to increased serum amylase; in a study it was shown that $10 \%$ to $15 \%$ cases of ketoacidosis resulted in acute pancreatitis and increase in serum amylase [5]. However, currently the main and effective treatment for diabetes mellitus is the use of insulin and hypoglycemic agents, but these compounds have numerous adverse effects such as increased fat stores, lipoatrophy (atrophy of fat tissue at the site of injection), and hypoglycemic shock and likely do not have efficacy on the side effects of diabetes [6].

Compounds isolated from plants are used for the prevention and treatment of some diseases such as diabetes [7]. Although medicinal plants and their derivatives are used traditionally in the treatment of diabetes and its complications, credible evidence has not been found regarding the effectiveness of many of them [8]. Medicinal plants like synthetic drugs may have unwanted side effects and make irreparable tissue damage [9]. 
Marigold (Calendula officinalis L.) belongs to the family of Asteraceae. It is similar to sunflowers and while it grows as native in the Middle East, it is planted as an ornamental plant in most parts of the world [10, 11]. Different species of this herb have compounds such as phenolics, terpenoids, tocopherols, carotenoids, quinones, coumarins, and volatile oil and benefit therapeutic effects from many of them have been reported $[12,13]$. Amongst the therapeutic properties of marigold anti-inflammatory effect, pain relief, and wound healing can be noted; this herb is also used to treat disorders of the gastrointestinal tract, such as duodenal ulcer and gastric ulcer [14]. In addition, this plant has anti-inflammatory, antibacterial, antifungal, anticancer, and antioxidant properties [13]. Previous studies have shown that the methanolic extract of marigold flower and its isolated 1-butanol extract along with its hydroalcoholic leaf extract have hypoglycemic effects $[15,16]$. In addition, previous studies have reported the antioxidant property of in vitro and in vivo extracts obtained from this plant [17, 18]. For example, its hydroalcoholic extract inhibited DPPH (82.58\%) under in vitro conditions. Probably the antioxidant property of marigold is due to its phenolic compounds [19]. In previous studies the therapeutic effects of these compounds (phenol) such as antioxidant, anticancer, and anti-inflammatory effects have been demonstrated [20].

Considering that diabetes is associated with impaired pancreatic function, in this study we investigated the effects hydroalcoholic extract of marigold flower on serum level creatine kinase-MB (CK-MB), total CK, lipase, and amylase in STZ-induced diabetic rats. This study is also in line with our recent studies on diabetes complications, including insulin resistance [21], dyslipidemia [22], protein glycation [23], trace element changes [24], peroxidane/antioxidane balance [25], and the mechanisms of plant ingredients in the treatment of diabetes mellitus [26].

\section{Material and Method}

2.1. Preparation of Hydroalcoholic Extract. Marigold flowers were prepared from Ahvaz city, southwest of Iran, during October 2014. Hydroalcoholic extract of marigold flower was obtained by maceration method [27]. At first flowers of marigold were completely dried in the shade and subsequently with grinder were chopped. Prepared powder was soaked in $70 \%$ ethanol-30\% water for $72 \mathrm{~h}$. In the next stage, was fully concentrated by rotary machine and then obtained extract of hydroalcoholic marigold flower with putting in freezer dryer.

2.2. Animals. 36 male adult Wistar rats $(210 \pm 9 \mathrm{gr})$ were purchased from the research center and experimental animal house of Ahvaz Jundishapur University of Medical Sciences. In order to comply with the experimental condition, the animals were placed in the environment one week before the study start. The animals were housed in standard cages at room ambient temperature $\left(22^{\circ}-25^{\circ} \mathrm{C}\right)$ and humidity $(45-$ $50 \%$ ) along with $12 / 12 \mathrm{~h} \mathrm{light/dark} \mathrm{cycle} \mathrm{during} \mathrm{experiment}$ course. They were fed standard rat chow with water freely accessible.
2.3. Experimental Diabetes Induction. Diabetes was induced through intraperitoneal injection (IP) of streptozotocin (Sigma Aldrich, St Louis, MO, USA), at a dose of $60 \mathrm{mg} / \mathrm{kg}$, dissolved in normal saline. The symptoms such as polydipsia and polyuria after $72 \mathrm{~h}$ appeared. Then blood glucose was measured through sampling from the tail vein with a glucometer (EasyGluco Blood Glucose Meter-2657A). Diabetic animals were considered with serum glucose above $250 \mathrm{mg} / \mathrm{dL}$, while normal nondiabetic animals were considered with serum glucose at $108-137 \mathrm{mg} / \mathrm{dL}$ range [21].

2.4. Experimental Procedure. Thirty-six male Wistar rats were categorized into four groups $(n=9)$ : Group 1: control rats, which received only normal saline; Group 2: the diabetic rats which only received normal saline; Group 3: diabetic rats, which were treated with $250 \mathrm{mg} / \mathrm{kg}$ hydroalcoholic extract of C. officinalis L. flower; and Group 4: diabetic rats, which were treated with $500 \mathrm{mg} / \mathrm{kg}$ hydroalcoholic extract of L. flower. The different concentrations of the extract ( 250 or $500 \mathrm{mg} / \mathrm{kg}$ ) were orally administered by gavage at a certain time of day during 4 weeks.

2.5. Biochemical Analysis. At the end of study course (4 weeks), the animals were anesthetized with ketamine and xylazine followed by sampling performed through cardiac puncture with sterile syringe. The blood samples were centrifuged ( $3500 \mathrm{RPM}, 5 \mathrm{~min}$ ); then serums were separated and stored in $-20^{\circ} \mathrm{C}$. For measurement of total CK, CK-MB, amylase, and lipase in serum, we used commercial kits (Pars Azmoon, Tehran, Iran) by automatic analyzer (Biotechnica BT-3000 Plus Chemistry Analyzer, Italy).

2.6. Statistics. All results are presented as mean \pm SEM. The difference among mean values in all groups was assessed by one-way ANOVA followed by LSD test using SPSS software version 16.0. $p$ value $<0.05$ as significantly different was considered.

\section{Results}

3.1. Body Weight. As shown in Table 1, the mean value of body weight was significantly decreased in STZ-induced diabetic rats compared to the control group after 4 weeks $(p \leq 0.05)$. It was also observed that, in the animals treated with marigold hydroalcoholic extract, the body weight in dose-dependent manner toward normal level was improved (about $91.7 \%$ and $95.9 \%$ for groups treated by 250 and $500 \mathrm{mg} / \mathrm{kg}$ hydroalcoholic extract, resp.).

3.2. Cardiac Biomarkers. Table 2 shows level of cardiac biomarkers in experimental and control groups after 28 days' treatment. The results were determined such that they had significant difference at the end of study. In diabetic rats, total creatine kinase (total CK) level was significantly higher than other groups $(p \leq 0.05)$, but treatment with $250 \mathrm{mg} / \mathrm{kg}$ extract led to its significant decrease compared to normal rats (54.5\%) ( $p \leq 0.05)$. In addition, the best result was showed in the group treated with $500 \mathrm{mg} / \mathrm{kg}$ hydroalcoholic extract, 
TABLE 1: Effect of hydroalcoholic flower extract of marigold on body weight in control and experimental group.

\begin{tabular}{lcc}
\hline \multirow{2}{*}{ Group $(N=9)$} & \multicolumn{2}{c}{ Mean body weight $(\mathrm{gr})$} \\
& Initial weight & Final weight \\
\hline NC & $231.43 \pm 51.065$ & $234.44 \pm 44.472$ \\
DC & $199.23 \pm 67.210$ & $177.55 \pm 43.946^{*}$ \\
T250 & $223.14 \pm 16.325$ & $215.00 \pm 34.550^{* *}$ \\
T500 & $229.65 \pm 58.419$ & $225.11 \pm 22.418^{* *}$ \\
\hline
\end{tabular}

NC: normal control group; DC: diabetic control group; T250: diabetic rat treated with $250 \mathrm{mg} / \mathrm{kg}$ extract; T500: diabetic rat treated with $500 \mathrm{mg} / \mathrm{kg}$ extract; values are presented as mean $\pm \mathrm{SD} ; n=9$ in each group. One-way ANOVA followed by LSD test $(p<0.05) .{ }^{*}$ Significant difference with NC. ${ }^{* *}$ Significant difference with DC.

TABLE 2: Effect of hydroalcoholic extract of marigold flower on cardiac biomarkers in different groups after 28 days' treatment.

\begin{tabular}{lcc}
\hline \multirow{2}{*}{ Group $(N=9)$} & \multicolumn{2}{c}{ Mean of cardiac biomarkers } \\
& Total CK $(\mathrm{U} / \mathrm{L})$ & CK-MB $(\mathrm{U} / \mathrm{L})$ \\
\hline NC & $63.57 \pm 3.713$ & $323.04 \pm 6.777$ \\
DC & $170.81 \pm 17.541^{*}$ & $469.95 \pm 2.402^{*}$ \\
T250 & $93.13 \pm 2.854^{* *}$ & $409.57 \pm 10.855^{* *}$ \\
T500 & $74.90 \pm 3.810^{* *}$ & $402.64 \pm 6.520^{* *}$ \\
\hline
\end{tabular}

NC: normal control group; DC: diabetic control group; T250: diabetic rat treated with $250 \mathrm{mg} / \mathrm{kg}$ extract; T500: diabetic rat treated with $500 \mathrm{mg} / \mathrm{kg}$ extract; values are presented as mean $\pm \mathrm{SD} ; n=9$ in each group. One-way ANOVA followed by LSD test $(p<0.05) .{ }^{*}$ Significant difference with NC. ${ }^{* *}$ Significant difference with DC.

in which approximately $43.8 \%$ reduction was found. We also measured the level of serum creatine kinase-MB (CK-MB) activity in all groups at the end of study time course. Analyses of results were determined such that its level was significantly incremented in diabetic group compared to normal rats $(p \leq$ $0.05)$. Treatment with hydroalcoholic extract of marigold flower (250 or $500 \mathrm{mg} / \mathrm{kg}$ for 4 weeks) resulted in dramatic changes during period of study ( $p \leq 0.05)$. In addition, a dose-dependent manner was determined, so that, in the group treated by $500 \mathrm{mg} / \mathrm{kg}$ extract, the level of creatine kinase-MB was lower than that in the animals treated by $250 \mathrm{mg} / \mathrm{kg}$ extract.

3.3. Pancreatic Biomarkers. We also measured amylase and lipase activity in the serum for determination of pancreas function during diabetes condition. As shown in Table 3, induction of diabetes was associated with significant difference in the serum level of pancreatic biomarkers. In the diabetic animals amylase and lipase levels were lower and higher than control group, respectively, while treatment with $250 \mathrm{mg} / \mathrm{kg}$ extract resulted in increase of amylase level along with decrease of lipase level after 28 days. In addition, we also observed raised amylase level accompanied with significant reduction of lipase level in the group treated with $500 \mathrm{mg} / \mathrm{kg}$ hydroalcoholic extract compared to control group $(p \leq 0.05)$.
TABLE 3: Effect of hydroalcoholic flower extract of marigold on serum activity of amylase and lipase in control and experimental group after 4 weeks' treatment.

\begin{tabular}{lcc}
\hline \multirow{2}{*}{ Group $(N=9)$} & \multicolumn{2}{c}{$\begin{array}{c}\text { Mean of pancreatic biomarkers } \\
\text { Amylase }(\mathrm{U} / \mathrm{dL})\end{array}$} \\
\hline NC & $15.81 \pm 1.187$ & $153.08 \pm 5.251$ \\
DC & $13.63 \pm 1.442^{*}$ & $432.21 \pm 13.295^{*}$ \\
T250 & $14.08 \pm 0.593$ & $264.46 \pm 5.479^{* *}$ \\
T500 & $14.33 \pm 0.698$ & $233.94 \pm 68.764^{* *}$ \\
\hline
\end{tabular}

NC: normal control group; DC: diabetic control group; T250: diabetic rat treated with $250 \mathrm{mg} / \mathrm{kg}$ extract; T500: diabetic rat treated with $500 \mathrm{mg} / \mathrm{kg}$ extract; values are presented as mean $\pm \mathrm{SD} ; n=9$ in each group. One-way ANOVA followed by LSD test $(p<0.05) .{ }^{*}$ Significant difference with NC. ${ }^{* *}$ Significant difference with DC.

\section{Discussion}

In this study, we investigated the protective effects of hydroalcoholic extract of marigold flower under diabetic condition during 4 weeks. Deficiency of insulin during diabetes decreases synthesis of proteins and is followed by occurrence of catabolism of structure proteins and ultimately resulted in body weight loss [28-30]. The results showed that mean value of body weight was dramatically decreased in the diabetic rats without treatment after 4 weeks while body weight was normalized by treatment with hydroalcoholic extract of marigold flower (205 and $500 \mathrm{mg} / \mathrm{kg}$ i.p.) at the end of study time course (Table 1).

As oxidative stress resulted from hyperglycemia, therefore people with diabetes encounter dysfunctions of tissue $[31,32]$. The destruction of beta cells and reduction of insulin production make diabetes. STZ is a most common ingredient that is used for developing diabetes and it has been showed that it leads to oxidative stress by increase of ROS and the development of diabetes complications [32-34]. Yoshikawa et al, 2001, examined the administration of $1000 \mathrm{mg} / \mathrm{kg}$ of methanol extract of Calendula officinalis and $500 \mathrm{mg} / \mathrm{kg} \mathrm{n}$ butanol extract isolated from its significantly reduced blood glucose in glucose-loaded rats [15]. In addition, it has been showed that hydroalcoholic extract obtained from the leaves of marigold significantly reduced blood glucose, cholesterol, and phospholipids in the diabetic rats with alloxan [16].

Under diabetes condition, increased blood sugar by changes in gene expression leads to myocardial cell death; it has also been observed that the main reason for changes is oxidant-antioxidant imbalance [35]. Examination of creatine kinase activity in different tissues suggests that during diabetes it reduced its activity in the heart, brain, and extensor digitorum longus. Indeed, diabetes leads to change in the function of creatine kinase and ultimately impairment in energy metabolism [36]. In 1999, Spindler and colleagues also confirmed the activity reduction of creatine kinase in diabetic cardiomyopathy due to energy shortage [37]. As we found that body weight loss occurred during diabetes induction, thus lack of energy resulted in complication such as myocardial cell death and releasing cardiac biomarker into blood circulation. In addition, our results showed that 
marigold improved the level of creatine kinase-MB and total creatine kinase as cardiac biomarkers under diabetes condition. Probably it is effective for reduction of side effects during diabetes (Table 2). Previous studies confirmed the presence of flavonoids such as quercetin, isoquercetin, isorhamnetin, narcissin, rutin, and calendoflavobioside [38-40]. Those are also responsible for antioxidant activity in this herb, so that the extracts made from flower and petal of marigold through high antioxidant activity prevented lipid proxidation [13]. In addition, another reason for its antioxidant activity is presence of carotenoids [41]. The use of antioxidants can reduce the side effects of diabetes such as cardiovascular problems; for example, in a study it was examined that administration of $100 \mathrm{mg} / \mathrm{kg}$ Ginkgo biloba extract raised the activity of creatine kinase in diabetic rats with streptozotocin [42]. Also administration of green tea for 4 weeks led to a reduction of serum creatine kinase to normal level under conditions of diabetes [43]. A research group investigated the effect of fraction 1 of acetone extract Cassia glauca leaf on STZ-induced diabetic rats. The results showed that it had hypoglycemic effects accompanied by improvement in enzymes level of ALT, AST, and CK [44]. Moreover, in other conditions such as exercise training that is effective in the oxidant-antioxidant balance it was showed that it could lead to improvement of total creatine kinase (CK), CK-MM, and CK-MB enzymes activities in the heart of streptozotocin-induced diabetic rats $[45,46]$.

After injection of STZ, changes occur in pancreatic exocrine secretion, so that, five days after injection, the serum level of lipase increases, while insulin injection leads to moderation of change; thus the lack of insulin is effective in activity of lipolytic enzymes gastrointestinal tract [47]. In addition, several studies showed that, in models of diabetes with failure for production or resistance of insulin, the activity of amylase in acinar cells was decreased, but lipase activity in pancreatic acinar cell was increased. The reductions of amylase expression along with increment of lipase expression were results that were also confirmed [48-53]. In several studies it has been reported that insulin deficiency resulted in pancreatic exocrine dysfunction [53-56]. In our examination, the serum levels of amylase and lipase as pancreatic biomarkers in the groups treated with hydroalcoholic flower extract of marigold dramatically normalized compared to normal control group (Table 3). Perhaps extract protects from pancreas (special beta cells) against toxicity induced by STZ, and followed by insulin level and energy shortage normalizes and ultimately resulted in improvement of body weight loss and releasing reduction of pancreatic biomarkers. In fact, we report that pancreatic exocrine-endocrine relationship is very important in pathology diabetes. It is seems that marigold has benefit effect for reduction of side effect in diabetes condition.

Considering that previous studies have proved antioxidant property of marigold, thus probably these effects are due to reduction level of oxidant and protection of the pancreas $[13,41,57]$. In relation to other herbs with antioxidant property it has been observed that extracts of kernel and husk neem lead to lower level of increased creatine kinase in diabetic rats [32]. Study Ohaeri, 2001, also investigated effect of garlic oil on diabetic rats with STZ. The results confirmed that there was decreased level of serum amylase under diabetes condition [58].

\section{Conclusion}

According to this study, we conclude that pancreatic dysfunction resulted in changes of serum level of cardiac and pancreatic biomarkers. In addition, marigold can reduce the side effects of diabetes by normalization of creatine kinase (CK-MB and total CK), amylase, and lipase in the diabetic rats, but further studies need to be performed for better understanding of marigold effects on diabetes.

\section{Conflict of Interests}

The authors declare that there is no conflict of interests regarding the publication of this paper.

\section{Acknowledgments}

The authors thank our colleague in Health Research Institute, Diabetes Research center, for corporation of this research. In addition, we appreciate Student Research Committee for provided financial support.

\section{References}

[1] S. Kadan, B. Saad, Y. Sasson, and H. Zaid, "In vitro evaluations of cytotoxicity of eight antidiabetic medicinal plants and their effect on GLUT4 translocation," Evidence-based Complementary and Alternative Medicine, vol. 2013, Article ID 549345, 9 pages, 2013.

[2] M. Kim, E. Kim, H. S. Kwak, and Y. Jeong, "The ingredients in Saengshik, a formulated health food, inhibited the activity of $\alpha$ amylase and $\alpha$-glucosidase as anti-diabetic function," Nutrition Research and Practice, vol. 8, no. 5, pp. 602-606, 2014.

[3] L. Guariguata, D. R. Whiting, I. Hambleton, J. Beagley, U. Linnenkamp, and J. E. Shaw, "Global estimates of diabetes prevalence for 2013 and projections for 2035," Diabetes Research and Clinical Practice, vol. 103, no. 2, pp. 137-149, 2014.

[4] R. Bazin and M. Lavau, "Diet composition and insulin effect on amylase to lipase ratio in pancreas of diabetic rats," Digestion, vol. 19, no. 6, pp. 386-391, 1979.

[5] S. Nair, D. Yadav, and C. S. Pitchumoni, "Association of diabetic ketoacidosis and acute pancreatitis: observations in 100 consecutive episodes of DKA," The American Journal of Gastroenterology, vol. 95, no. 10, pp. 2795-2800, 2000.

[6] G. Suji and S. Sivakami, "Approaches to the treatement of diabetes mellitus: an overview," Cellular and Molecular Biology, vol. 49, no. 4, pp. 635-639, 2003.

[7] M. E. Waltner-Law, X. L. Wang, B. K. Law, R. K. Hall, M. Nawano, and D. K. Granner, "Epigallocatechin gallate, a constituent of green tea, represses hepatic glucose production," The Journal of Biological Chemistry, vol. 277, no. 38, pp. 3493334940, 2002.

[8] K. Shapiro and W. C. Gong, "Natural products used for diabetes," Journal of the American Pharmaceutical Association, vol. 42, no. 2, pp. 217-226, 2002. 
[9] P. A. G. M. De Smet, “The role of plant-derived drugs and herbal medicines in healthcare," Drugs, vol. 54, no. 6, pp. 801-840, 1997.

[10] S. Khiljee, S. Rehman, T. Khiljee, and U. Qureshi, "Use of traditional herbal medicines in the treatment of eczema," Journal of Pakistan Association of Dermatologists, vol. 21, no. 2, pp. 112-117, 2011.

[11] A. Ramos, A. Edreira, A. Vizoso, J. Betancourt, M. López, and M. Décalo, "Genotoxicity of an extract of Calendula officinalis L., Journal of Ethnopharmacology, vol. 61, no. 1, pp. 49-55, 1998.

[12] F. V. Dulf, D. Pamfil, A. D. Baciu, and A. Pintea, "Fatty acid composition of lipids in pot marigold (Calendula officinalis L.) seed genotypes," Chemistry Central Journal, vol. 7, no. 1, article 8, 2013.

[13] B. P. Muley, S. S. Khadabadi, and N. B. Banarase, "Phytochemical constituents and pharmacological activities of Calendula officinalis Linn (Asteraceae): a review," Tropical Journal of Pharmaceutical Research, vol. 8, no. 5, pp. 455-465, 2009.

[14] M. Kratchanova, P. Denev, M. Ciz, A. Lojek, and A. Mihailov, "Evaluation of antioxidant activity of medicinal plants containing polyphenol compounds. Comparison of two extraction systems," Acta Biochimica Polonica, vol. 57, no. 2, pp. 229-234, 2010.

[15] M. Yoshikawa, T. Murakami, A. Kishi, T. Kageura, and H. Matsuda, "Medicinal flowers. III. Marigold.(1): hypoglycemic, gastric emptying inhibitory, and gastroprotective principles and new oleanane-type triterpene oligoglycosides, calendasaponins A, B, C, and D, from Egyptian Calendula officinalis," Chemical and Pharmaceutical Bulletin, vol. 49, no. 7, pp. 863-870, 2001.

[16] R. Arora and C. Majee, "Antidiabetic and antihyperlipidaemic effect of hydro-alcoholic extract of Calendula officinalis," International Research Journal of Pharmacy, vol. 2, no. 1, pp. 61-65, 2011.

[17] C. A. S. Cordova, I. R. Siqueira, C. A. Netto et al., "Protective properties of butanolic extract of the Calendula officinalis L. (marigold) against lipid peroxidation of rat liver microsomes and action as free radical scavenger," Redox Report, vol. 7, no. 2, pp. 95-102, 2002.

[18] A. Herold, L. Cremer, A. Calugăru et al., "Antioxidant properties of some hydroalcoholic plant extracts with antiinflammatory activity," Roumanian Archives of Microbiology and Immunology, vol. 62, no. 3-4, pp. 217-227, 2002.

[19] A. Singh, K. Agarwal, and P. Saini, "In vitro antioxidant activity of different extracts of Calendula officinalis leaves," Journal of Drug Delivery and Therapeutics, vol. 4, no. 4, pp. 74-76, 2014.

[20] K. D. Croft, "Antioxidant effects of plant phenolic compounds," in Antioxidants in Human Health and Disease, pp. 109-121, CABI Publishing, New York, NY, USA, 1999.

[21] S. Shirali, S. Z. Bathaie, and M. Nakhjavani, "Effect of crocin on the insulin resistance and lipid profile of streptozotocininduced diabetic rats," Phytotherapy Research, vol. 27, no. 7, pp. 1042-1047, 2013.

[22] S. Shirali, S. Bathaei, M. Nakhjavani, and M. Ashoori, "Effects of saffron (Crocus sativus L.) aqueous extract on serum biochemical factors in streptozotocin-induced diabetic rats," Iranian Journal of Medicinal and Aromatic Plants, vol. 28, pp. 293-308, 2012.

[23] S. S. Mahsa Sharifat and P. Ebadi, "Investigation of changes in levels of AGEs and $\beta 2$-microglobulin in patients with type 2 diabetes," Journal of Academic and Applied Studies, vol. 4, no. 9, pp. 1-10, 2014.

[24] R. Mahdizadeh, S. Shirali, and P. Ebadi, "Investigation of imbalance of trace elements in patients with type 2 diabetes mellitus,"
Journal of Academic and Applied Studies, vol. 4, no. 9, pp. 11-21, 2014.

[25] A. Barari, M. Fakori Joybari, S. Shirali, M. Shojaee, and A. Khandandel, "Effect of eight-week consumption of purslane extract on peroxidane/antioxidant balance in women with type 2 diabetes," Medical Laboratory Journal, vol. 8, no. 2, pp. 1-7, 2014.

[26] S. Z. Bathaie, N. Mokarizade, and S. Shirali, "An overview of the mechanisms of plant ingredients in the treatment of diabetes mellitus," Journal of Medicinal Plants, vol. 11, no. 44, pp. 1-24, 2012.

[27] R. K. Kath and R. K. Gupta, "Antioxidant activity of hydroalcoholic leaf extract of Ocimum sanctum in animal models of peptic ulcer," Indian Journal of Physiology and Pharmacology, vol. 50, no. 4, article 391, 2006.

[28] S. Gurudeeban and T. Ramanathan, "Antidiabetic effect of Citrullus colocynthis in alloxon-induced diabetic rats," Inventi Rapid: Ethnopharmacology, vol. 1, no. 1, p. 112, 2010.

[29] V. Vats, S. P. Yadav, and J. K. Grover, "Ethanolic extract of Ocimum sanctum leaves partially attenuates streptozotocininduced alterations in glycogen content and carbohydrate metabolism in rats," Journal of Ethnopharmacology, vol. 90, no. 1, pp. 155-160, 2004.

[30] H. Ashraf, R. Heidari, V. Nejati, and M. Ilkhanipoor, "Effects of aqueous extract of Berberis integerrima root on some physiological parameters in streptozotocin-induced diabetic rats," Iranian Journal of Pharmaceutical Research, vol. 12, no. 2, pp. 425-434, 2013.

[31] I. C. West, "Radicals and oxidative stress in diabetes," Diabetic Medicine, vol. 17, no. 3, pp. 171-180, 2000.

[32] S. Gupta, M. Kataria, P. K. Gupta, S. Murganandan, and R. C. Yashroy, "Protective role of extracts of neem seeds in diabetes caused by streptozotocin in rats," Journal of Ethnopharmacology, vol. 90, no. 2-3, pp. 185-189, 2004.

[33] J. Kawada, "New hypotheses for the mechanisms of streptozotocin and alloxan inducing diabetes mellitus," Journal of the Pharmaceutical Society of Japan, vol. 112, no. 11, pp. 773-791, 1992.

[34] V. Ukwenya, O. Ashaolu, D. Adeyemi et al., "Evaluation of antioxidant potential of methanolic leaf extract of Anacardium occidentale (Linn) on the testes of streptozotocin-induced diabetic wistar rats," European Journal of Anatomy, vol. 17, no. 2, pp. 72 81, 2013.

[35] L. Cai and Y. J. Kang, "Oxidative stress and diabetic cardiomyopathy," Cardiovascular Toxicology, vol. 1, no. 3, pp. 181-193, 2001.

[36] X. Zhao, M. Bassirat, K. Zeinab, and R. D. Helme, "Effects of diabetes on creatine kinase activity in streptozotocin-diabetic rats," Chinese Medical Journal, vol. 112, no. 11, pp. 1028-1031, 1999.

[37] M. Spindler, K. W. Saupe, R. Tian, S. Ahmed, M. A. Matlib, and J. S. Ingwall, "Altered creatine kinase enzyme kinetics in diabetic cardiomyopathy. $\mathrm{A}^{31} \mathrm{P}$ NMR magnetization transfer study of the intact beating rat heart," Journal of Molecular and Cellular Cardiology, vol. 31, no. 12, pp. 2175-2189, 1999.

[38] V. A. Kurkin and O. V. Sharova, "Flavonoids from Calendula officinalis flowers," Chemistry of Natural Compounds, vol. 43, no. 2, pp. 216-217, 2007.

[39] E. Vidal-Ollivier, R. Elias, F. Faure et al., "Flavonol glycosides from Calendula officinalis flowers," Planta Medica, vol. 55, no. 1, pp. 73-74, 1989. 
[40] M. Ukiya, T. Akihisa, K. Yasukawa, H. Tokuda, T. Suzuki, and Y. Kimura, "Anti-inflammatory, anti-tumor-promoting, and cytotoxic activities of constituents of marigold (Calendula officinalis) flowers," Journal of Natural Products, vol. 69, no. 12, pp. 1692-1696, 2006.

[41] A. Pintea, C. Bele, S. Andrei, and C. Socaciu, "HPLC analysis of carotenoids in four varieties of C. officinalis L. flowers," Acta Biologica Szegediensis, vol. 47, no. 1-4, pp. 37-40, 2002.

[42] G. Fitzl, R. Martin, D. Dettmer, V. Hermsdorf, H. Drews, and K. Welt, "Protective effects of Gingko biloba extract EGb 761 on myocardium of experimentally diabetic rats. I. Ultrastructural and biochemical investigation on cardiomyocytes," Experimental and Toxicologic Pathology, vol. 51, no. 3, pp. 189-198, 1999.

[43] P. V. A. Babu, K. E. Sabitha, P. Srinivasan, and C. S. Shyamaladevi, "Green tea attenuates diabetes induced Maillard-type fluorescence and collagen cross-linking in the heart of streptozotocin diabetic rats," Pharmacological Research, vol. 55, no. 5, pp. 433-440, 2007.

[44] M. Farswan, P. M. Mazumder, and V. Percha, "Protective effect of Cassia glauca Linn. on the serum glucose and hepatic enzymes level in streptozotocin induced NIDDM in rats," Indian Journal of Pharmacology, vol. 41, no. 1, pp. 19-22, 2009.

[45] M. Atalay and D. E. Laaksonen, "Diabetes, oxidative stress and physical exercise," Journal of Sports Science \& Medicine, vol. 1, no. 1, pp. 1-14, 2002.

[46] N. Mokhtar, S. Rousseau-Migneron, G. Tancrède, and A. Nadeau, "Partial correction of impaired creatine kinase activity in diabetic rat heart by physical training," Metabolism, vol. 41, no. 9, pp. 1004-1008, 1992.

[47] R. D. Duan and B. Sternby, "Decrease in contents of pancreatic carboxyl ester lipase, phospholipase A2, and lingual lipase in rats with streptozotocin-induced diabetes," Scandinavian Journal of Gastroenterology, vol. 28, no. 3, pp. 256-260, 1993.

[48] M. Bendayan and E. Levy, "Immunocytochemical and biochemical evaluation of pancreatic lipase in acinar cells of control and streptozotocin-induced diabetic rats," Pancreas, vol. 3, no. 3, pp. 269-273, 1988.

[49] A. A. Aughsteen, K. Kataoka, and S. A. Shair, "Correlative morphometric and biochemical study on pancreatic amylase in normal and streptozotocin-diabetic rats," Pancreas, vol. 13, no. 3, pp. 295-303, 1996.

[50] R.-D. Duan, J. Poensgen, C. Wicker, B. Weström, and C. Erlanson-Albertsson, "Increase in pancreatic lipase and trypsin activity and their mRNA levels in streptozotocin-induced diabetic rats," Digestive Diseases and Sciences, vol. 34, no. 8, pp. 1243-1248, 1989.

[51] R.-D. Duan and C. Erlanson-Albertsson, "Pancreatic lipase and colipase activity increase in pancreatic acinar tissue of diabetic rats," Pancreas, vol. 4, no. 3, pp. 329-334, 1989.

[52] K. Nakajima, T. Nemoto, T. Muneyuki, M. Kakei, H. Fuchigami, and H. Munakata, "Low serum amylase in association with metabolic syndrome and diabetes: a community-based study," Cardiovascular Diabetology, vol. 10, article 34, 2011.

[53] K. Burski, T. Ueland, and R. Maciejewski, "Serum amylase activity disorders in the course of experimental diabetes in rabbits," Veterinarni Medicina, vol. 49, no. 6, pp. 197-200, 2004.

[54] H. P. Harding, H. Zeng, Y. Zhang et al., "Diabetes mellitus and exocrine pancreatic dysfunction in Perk ${ }^{-/-}$mice reveals a role for translational control in secretory cell survival," Molecular Cell, vol. 7, no. 6, pp. 1153-1163, 2001.
[55] P. D. Hardt, A. Krauss, L. Bretz et al., "Pancreatic exocrine function in patients with type 1 and type 2 diabetes mellitus," Acta Diabetologica, vol. 37, no. 3, pp. 105-110, 2000.

[56] Å. Lernmark, "Rapid-onset type 1 diabetes with pancreatic exocrine dysfunction," The New England Journal of Medicine, vol. 342, no. 5, pp. 344-345, 2000.

[57] K. C. Preethi, G. Kuttan, and R. Kuttan, "Antioxidant potential of an extract of Calendula officinalis. Flowers in vitro. and in vivo," Pharmaceutical Biology, vol. 44, no. 9, pp. 691-697, 2006.

[58] O. C. Ohaeri, "Effect of garlic oil on the levels of various enzymes in the serum and tissue of streptozotocin diabetic rats," Bioscience Reports, vol. 21, no. 1, pp. 19-24, 2001. 

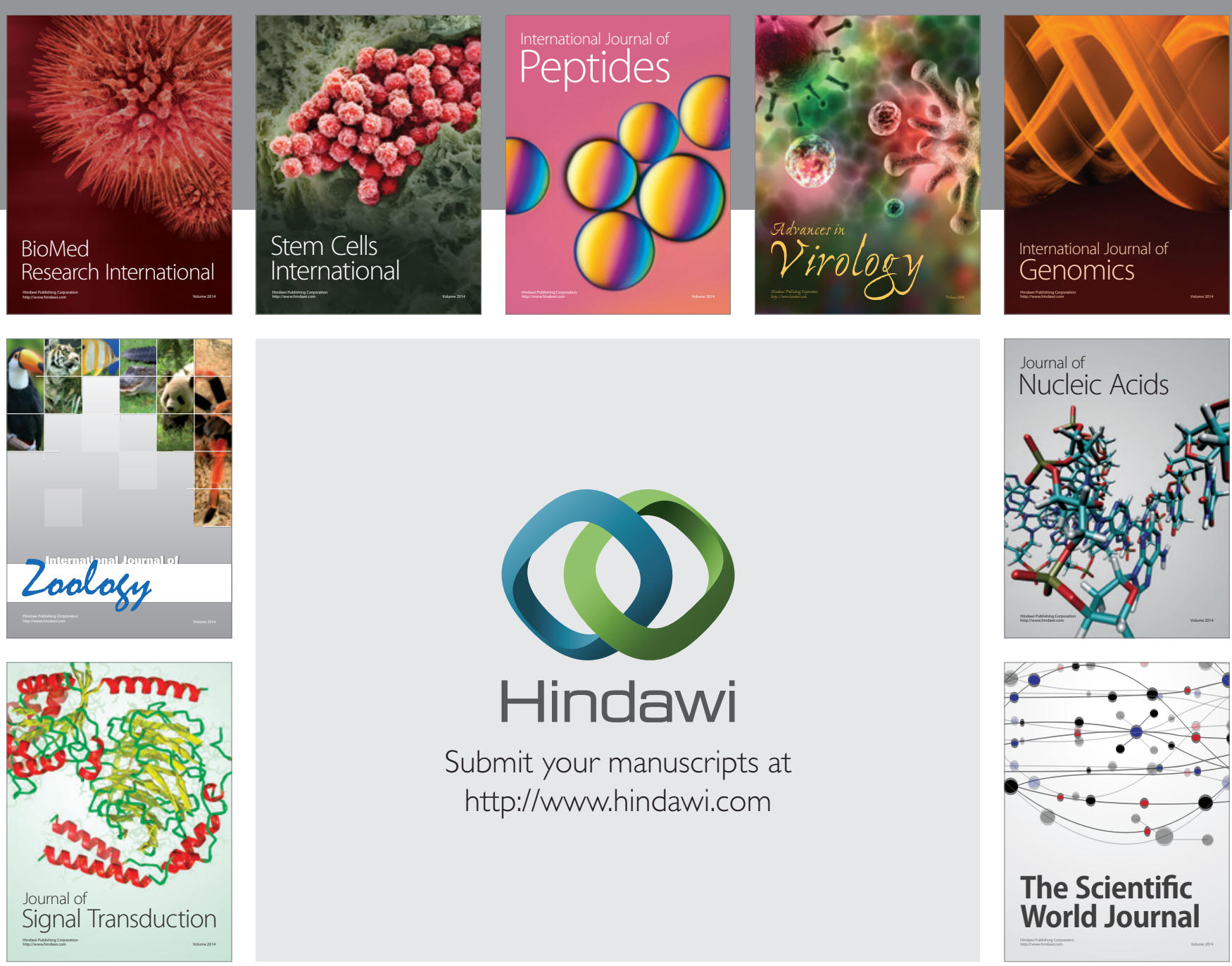

Submit your manuscripts at

http://www.hindawi.com
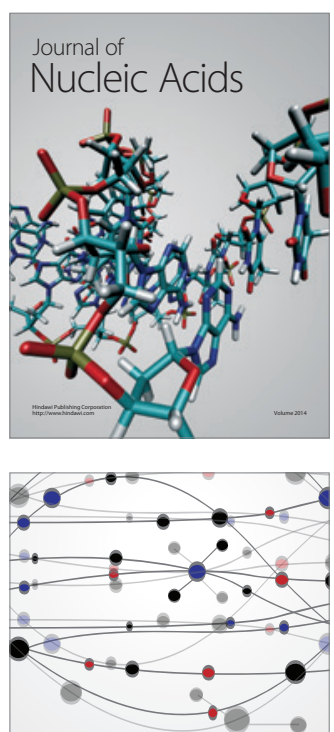

The Scientific World Journal
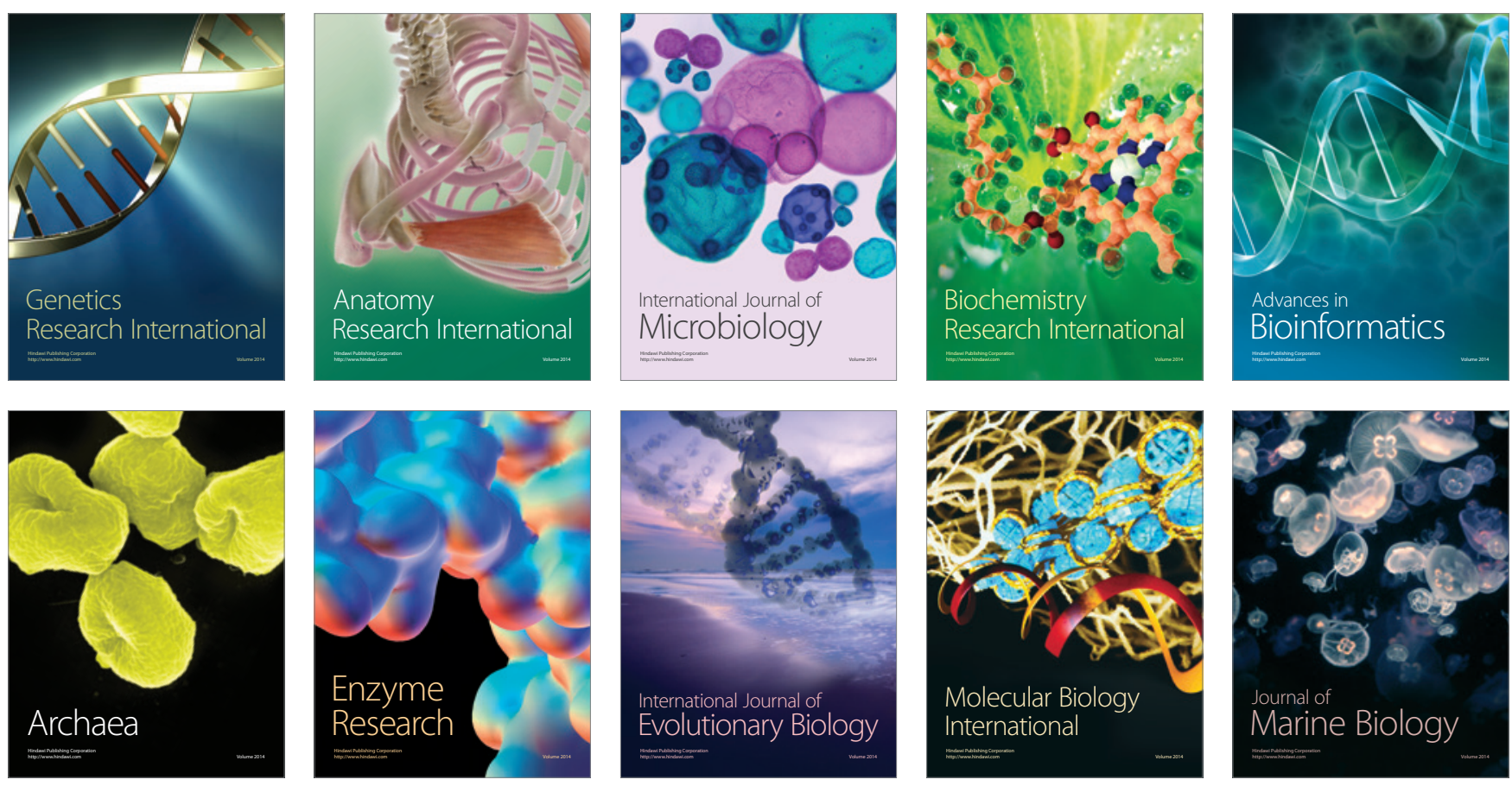